\title{
New Oral Anticoagulants May Be Particularly Useful for Asian Stroke Patients
}

\author{
Oh Young Bang, ${ }^{\mathrm{a}}$ Keun-Sik Hong, ${ }^{\mathrm{b}} \mathrm{Ji}$ Hoe Heo, ${ }^{\mathrm{c}}$ Jaseong Koo, ${ }^{\mathrm{d}}$ Sun U. Kwon, ${ }^{\mathrm{e}}$ Kyung-Ho Yu, ${ }^{\mathrm{f}}$ \\ Hee-Joon Bae, ${ }^{g}$ Byung-Chul Lee, ${ }^{\mathrm{f}}$ Byung-Woo Yoon, ${ }^{\mathrm{h}}$ Jong S. Kim ${ }^{\mathrm{e}}$ \\ ${ }^{a}$ Department of Neurology, Samsung Medical Center, Sungkyunkwan University School of Medicine, Seoul, Korea \\ bepartment of Neurology, Ilsan Paik Hospital, Inje University, Goyang, Korea \\ 'Department of Neurology, Yonsei University College of Medicine, Seoul, Korea \\ ${ }^{\mathrm{d}}$ Department of Neurology, Catholic University of Korea, College of Medicine, St. Mary's Hospital, Seoul, Korea \\ e'Department of Neurology, University of Ulsan College of Medicine, Seoul, Korea \\ ${ }^{\mathrm{f}}$ Department of Neurology, Hallym University College of Medicine, Anyang, Korea \\ ${ }^{\text {g}}$ Department of Neurology, Stroke Center, Seoul National University Bundang Hospital, Seongnam, Korea \\ ${ }^{\mathrm{h}}$ Department of Neurology, Seoul National University College of Medicine, Seoul, Korea
}

Atrial fibrillation (AF) is an emerging epidemic in both high-income and low-income countries, mainly because of global population aging. Stroke is a major complication of AF, and AF-related ischemic stroke is more disabling and more fatal than other types of ischemic stroke. However, because of concerns about bleeding complications, particularly intracranial hemorrhage, and the limitations of a narrow therapeutic window, warfarin is underused. Four large phase III randomized controlled trials in patients with non-valvular AF (RE-LY, ROCKET-AF, ARISTOTLE, and ENGAGE-AF-TIMI 48) demonstrated that new oral anticoagulants (NOACs) are superior or non-inferior to warfarin as regards their efficacy in preventing ischemic stroke and systemic embolism, and superior to warfarin in terms of intracranial hemorrhage. Among AF patients receiving warfarin, Asians compared to non-Asians are at higher risk of stroke or systemic embolism and are also more prone to develop major bleeding complications, including intracranial hemorrhage. The extra benefit offered by NOACs over warfarin appears to be greater in Asians than in non-Asians. In addition, Asians are less compliant, partly because of the frequent use of herbal remedies. Therefore, NOACs compared to warfarin may be safer and more useful in Asians than in non-Asians, especially in stroke patients. Although the use of NOACs in AF patients is rapidly increasing, guidelines for the insurance reimbursement of NOACs have not been resolved, partly because of insufficient understanding of the benefit of NOACs and partly because of cost concerns. The cost-effectiveness of NOACs has been well demonstrated in the healthcare settings of developed countries, and its magnitude would vary depending on population characteristics as well as treatment cost. Therefore, academic societies and regulatory authorities should work together to formulate a scientific healthcare policy that will effectively reduce the burden of AF-related stroke in this rapidly aging society.

Keywords Atrial fibrillation; Warfarin; Stroke; Intracranial hemorrhage; Asians; New oral anticoagulants
Correspondence: Jong S. Kim

Department of Neurology, University of

Ulsan College of Medicine, Asan Medical

Center, 88 Olympic-ro 43-gil, Songpa-gu,

Seoul 138-736, Korea

Tel: +82-2-3010-3442

Fax: +82-2-474-4691

E-mail: jongskim@amc.seoul.kr

Received: March 3, 2014

Revised: March 23, 2014

Accepted: March 29, 2014

The authors have no financial conflicts of interest. 


\section{Unmet need for anticoagulation: Alternatives to warfarin?}

Warfarin is highly effective in reducing stroke risk in patients with atrial fibrillation $(\mathrm{AF})$. However, using warfarin is not easy; effort is needed to educate patients about drug and dietary interactions, and serial monitoring of the international normalization ratio (INR) is required. As a result, poor compliance is a big problem in warfarin use. A recent population-based cohort study showed that $43 \%$ of patients stopped warfarin within 3 years and $61 \%$ within 5 years. ${ }^{1}$

In addition, warfarin has a narrow therapeutic threshold, and the quality of anticoagulation has a critical influence on its effect. In a UK cohort study, warfarin therapy with a time in therapeutic range (TTR) of INR of less than $60 \%$ did not significantly reduce stroke risk compared to no antithrombotic therapy. ${ }^{2}$ In a post hoc analysis of ACTIVE W (Atrial Fibrillation Clopidogrel Trial With Irbesartan for Prevention of Vascular Events), in order to ensure the superiority of warfarin over clopidogrel plus aspirin the minimum projected TTR threshold was $58 \% .{ }^{3}$ While suboptimal doses lead to an increased risk of ischemic stroke, overdosing frequently results in hemorrhage that can be fatal. Even in the setting of clinical trials, the reported TTRs were only about two thirds. ${ }^{47}$ It also has been shown that eight adverse bleeding events are estimated to occur annually for every 100 patients treated, ${ }^{8}$ and the underutilization of warfarin is in part due to concerns about hemorrhagic risk.

Lastly, the use of warfarin is particularly cumbersome in old subjects and in those with stroke. They are more vulnerable to bleeding complications that may be related with poor compliance, cognitive impairment, and the frequent presence of comorbid diseases that require polypharmacy and invasive procedures. In subjects undergoing invasive treatment, periprocedural management is difficult and carries a high risk for thromboembolism, partly because of the slow onset and offset of action (long half-life) of warfarin.

Therefore, more ideal anticoagulants are required that have a wide therapeutic range, a short half-life, and a predictable therapeutic effect with fixed or weight-based dosing, without significant food or drug interaction. ${ }^{9}$

\section{Results from major randomized clinical trials of new oral anticoagulants}

The first clinical study with warfarin was reported in 1955. In the meantime, several warfarin alternatives have been tested but failed to show benefits because of serious adverse effects, i.e., excessive bleeding with idraparinux ${ }^{10}$ or hepatic dysfunction with ximelagatran. ${ }^{11}$ New oral anticoagulants (NOACs) (dabigatran, apixaban, rivaroxaban, and edoxaban) were first introduced in 2005, for prophylaxis against venous thromboembolism after total hip or knee replacement surgery, and are now

Table 1. Current licensed indications for the new oral anticoagulants

\begin{tabular}{|c|c|c|c|c|}
\hline & \multicolumn{4}{|c|}{ New oral anticoagulants (phase III randomized clinical trials) } \\
\hline & Dabigatran & Rivaroxaban & Apixaban & Edoxaban \\
\hline $\begin{array}{l}\text { Prevention of stroke or systemic embolism in } \\
\text { adults with non-valvular atrial fibrillation }\end{array}$ & Approved (RE-LY) & Approved (ROCKET-AF) & $\begin{array}{l}\text { Approved (ARISTOTLE, } \\
\text { AVERROES) }\end{array}$ & $\begin{array}{c}\text { In process (ENGAGE AF } \\
\text { TIMI-48) }\end{array}$ \\
\hline $\begin{array}{l}\text { Prevention of deep vein thrombosis in adults } \\
\text { who have undergone elective hip/knee } \\
\text { replacement surgery }\end{array}$ & $\begin{array}{l}\text { Approved (REMODEL, } \\
\text { RE-NOVATE, RE-MOBILIZE, } \\
\text { RE-NOVATE II) }\end{array}$ & $\begin{array}{l}\text { Approved (RECORD1, } \\
\text { RECORD2, RECORD3, } \\
\text { RECORD4) }\end{array}$ & $\begin{array}{l}\text { Approved (ADVANCE-1, } \\
\text { ADVANCE-2, } \\
\text { ADVANCE-3) }\end{array}$ & $\begin{array}{c}\text { In process } \\
\text { (STARS E3/J-4/J-5) }\end{array}$ \\
\hline $\begin{array}{l}\text { Acute treatment and prevention of recurrence } \\
\text { of deep vein thrombus and pulmonary } \\
\text { embolism in adults }\end{array}$ & $\begin{array}{c}\text { Approved (RE-COVER-I, II, } \\
\text { RE-MEDY, RE-SONATE) }\end{array}$ & $\begin{array}{c}\text { Approved (EINSTEIN-DVT, } \\
\text { EINSTEIN-PE, } \\
\text { EINSTEIN-EXT) }\end{array}$ & $\begin{array}{l}\text { In Process (AMPLIFY, } \\
\text { AMPLIFY-EXT) }\end{array}$ & $\begin{array}{l}\text { In process } \\
\text { (HOKUSAI-VTE) }\end{array}$ \\
\hline $\begin{array}{l}\text { Prevention of atherothrombotic events following } \\
\text { acute coronary syndrome }\end{array}$ & & $\begin{array}{c}\text { Approved in EU (ATLAS ACS } \\
\text { 2-TIMI 51) }\end{array}$ & & \\
\hline
\end{tabular}

RE-LY, Randomized evaluation of long-term anticoagulant therapy (NCT00262600); ROCKET-AF, Rivaroxaban once-daily, oral, direct factor Xa inhibition compared with vitamin K antagonism for prevention of stroke and embolism trial in atrial fibrillation (NCTO0403767); ARISTOTLE, Apixaban for reduction in stroke and other thromboembolic events in atrial fibrillation (NCT00412984); AVERROES, Apixaban vs. aspirin in patients with atrial fibrillation and previous stroke or transient ischemic attack (NCT00496769); ENGAGE AF TIMI-48, Effective anticoagulation with factor Xa next generation in atrial fibrillation-thrombolysis in myocardial infarction study 48 (NCTO0781391); REMODEL, Oral dabigatran etexilate vs. subcutaneous enoxaparin for the prevention of venous thromboembolism after total knee replacement (NCT00168805); RE-NOVATE, Dabigatran etexilate vs. enoxaparin for prevention of venous thromboembolism after total hip replacement (NCT00168818); RE-MOBILIZE, Oral thrombin inhibitor dabigatran etexilate vs. North American enoxaparin regimen for prevention of venous thromboembolism after knee-replacement surgery (NCT00152971); RECORD, REgulation of Coagulation in ORthopedic Surgery to Prevent Deep Venous Thrombosis and Pulmonary Embolism (NCT00329628, NCT00332020, NCT00361894, NCT00362232); ADVANCE, Apixaban Dose Orally vs. ANtiCoagulation with Enoxaparin (NCT00371683, NCT00452530, NCT00423319); RE-COVER, Dabigatran vs. warfarin in the treatment of acute venous thromboembolism (NCT00 291330, NCT00680186); RE-MEDY, Dabigatran or warfarin for extended maintenance therapy of venous thromboembolism (NCT00329238); RE-SONATE, Dabigatran vs. placebo for extended maintenance therapy of venous thromboembolism (NCT00558259); EINSTEIN, Oral, direct Factor Xa inhibitor rivaroxaban in patients with acute symptomatic deep vein thrombosis or pulmonary embolism (NCT00439725, NCT00439777, NCT00439725); AMPLIFY, Apixaban after the initial Management of PuLmonary embollsm and deep vein thrombosis with First-line therapY (NCT00643201, NCT00633893); ATLAS ACS 2-TIMI, Anti-Xa Therapy to Lower cardiovascular events in addition to Aspirin with or without thienopyridine therapy in Subjects with Acute Coronary Syndrome (NCT00402597). 
used to prevent and treat deep vein thrombosis and pulmonary embolism (Table 1). ${ }^{12}$

More recently, four large phase III randomized controlled trials of NOACs (RE-LY, ROCKET-AF, ARISTOTLE, and ENGAGE-AF-TIMI 48) have been completed in patients with nonvalvular $\mathrm{AF}^{4-7}$ Overall, NOACs were superior or non-inferior to warfarin in the prevention of ischemic stroke and systemic embolism, but superior to warfarin in reducing hemorrhagic stroke. ${ }^{47}$ NOACs may be more beneficial among patients with AF-related stroke or transient ischemic attack (TIA); a recent meta-analysis showed that NOACs significantly reduced stroke or systemic embolism, as well as hemorrhagic stroke or major bleeding, in patients with $\mathrm{AF}$ and previous stroke or TIA. ${ }^{13}$ The relative risk reduction and the number needed to treat with NOACs vs. warfarin to reduce stroke/systemic embolism were estimated to be $14 \%$ and 134 patients; for avoiding hemorrhagic stroke the respective values were $57.9 \%$ and 139 patients. ${ }^{13}$ Evidence from these trials forms the basis for national and international guidelines for the management of patients with non-valvular AF in clinical practice. Although aspirin was preferred in patients with a low-risk of stroke, new and safer anticoagulants may lead to lowering of the threshold for anticoagulation. ${ }^{14}$

The selection of antithrombotic agent (warfarin vs. NOACs) should be individualized on the basis of risk factors, cost, tolerability, patient preference, potential for drug interactions, and other clinical characteristics such as renal function and TTR. ${ }^{15}$ It would be unnecessary to switch from warfarin to NOACs in patients who already achieve stable and good INR control with warfarin. Good anticoagulation control (TTR $>70 \%$ ) is associated with the best efficacy and safety of warfarin, ${ }^{2}$ and the recent meta-analysis of the four phase III NOACs trials showed that there was a greater relative reduction in major bleeding with NOACs when the TTR was less than $66 \%$ than when it was greater. ${ }^{16}$

\section{Viewing NOACs from Asian perspectives}

The use of NOACs may be more beneficial for Asian patients. First of all, it appears that Asians more often have cerebral small vessel disease, which is prone to bleeding. It has been shown that hemorrhagic stroke (intracerebral or subarachnoid hemorrhage), which accounts for $15 \%$ to $20 \%$ of strokes in whites, ${ }^{17}$ is more frequent among Asians. ${ }^{18}$ Death from hemorrhagic stroke is also much more common in Asians. ${ }^{19}$ The prevalence of cerebral microbleeds, which increase the risk of intracerebral hemorrhage on anticoagulation, also appears to be higher in Asian than in white population. ${ }^{20}$ The ethnic differences in bleedingprone small artery disease are in part related with the high prev- alence of uncontrolled hypertension or hypocholesterolemia in this region. ${ }^{21}$ Ethnic differences in the salt sensitivity of intracranial hemorrhage (ICH) have also been addressed. ${ }^{22}$ Whatever the reason, these small artery diseases predispose patients to cerebral bleeding when they are given antithrombotics; the presence of cerebral small artery diseases, such as lacunar infarcts, white matter ischemia or microbleeds, increases the risk of ICH in patients receiving antiplatelet agents ${ }^{23}$ or anticoagulants. ${ }^{24,25}$ A recent study showed a high prevalence of warfarin-associated ICH in Asians, even if the INR levels were comparable; the hazard ratio for ICH was 4.06 for Asians, and 2 for Hispanics and blacks compared to whites. ${ }^{26}$ Considering that NOACs have a lower bleeding risk than warfarin, the benefit of NOACs may be greater in Asian patients.

Second, Asians generally favor complementary treatment, such as herbal medication and healthy food. According to a study from Korea, $40 \%$ of patients who were initially treated in a large tertiary hospital tried additional herbal treatment after discharge. ${ }^{27}$ This is in strong contrast to a report from Canada, where patients with cerebrovascular diseases rarely used alternative medicine. ${ }^{28}$ A study from Hong Kong found that $26 \%$ of patients taking warfarin had ingested herbal remedies. ${ }^{29}$ This behavior probably results in significant warfarin-drug/food interaction, poor INR control, and may at least in part explain the lower TTR achievement in Asian (mean 54.5\%) than in nonAsian (66.2\%) patients in the RE-LY trial. ${ }^{30,31}$ As Asians more often had a lower (rather than higher) INR level, another explanation would be that Asian physicians tend to target a relatively low INR because of the fear of bleeding complications. Indeed, Japanese guidelines recommend a target INR of 1.6-2.6 for Japanese people. ${ }^{32}$ Whatever the reason, INR control is relatively poor in Asia, which also supports the notion that NOACs may be more suitable for Asians.

Finally, there has been evidence that population frequencies of genetic polymorphisms related with warfarin metabolism and action (e.g., CYP2C9 and VKORC1) differ according to ethnicities. ${ }^{33-35}$ Apart from being linked to ethnic variations in the required warfarin dose, these differences may also partly explain the poor INR control and the higher risk of ICH among Asians.

Recent studies report that NOACs may be particularly valuable in Asians compared to non-Asians. ${ }^{31,36,37}$ The RE-LY investigators reported that, among patients treated with warfarin, Asians (vs. non-Asians) had higher rates of ischemic stroke (by 2.1fold) as well as hemorrhagic stroke (by 2.4-fold), despite similar blood pressure, younger age, and relatively lower INR values. The magnitude of the benefit from dabigatran in the prevention of ischemic stroke and hemorrhagic was greater in Asians than in non-Asians. ${ }^{31}$ More recently, Chiang and colleagues reported 
a post-hoc analysis of the Asian population included in the RELY and ARISOTLE trials, which showed that, compared to non-Asians, Asians had a lower number needed to treat with NOACs vs. warfarin to reduce stroke/systemic embolism, and a higher number needed to treat to avoid hemorrhagic complications, favoring their use in Asians in terms of both efficacy and safety. ${ }^{38}$

\section{Using NOACs in Asian stroke patients may be cost-effective}

Cost-effectiveness analyses showed that NOACs are cost-effective relative to warfarin for stroke prevention in patients with $\mathrm{AF}$ and stroke/TIA. ${ }^{39-41}$ Cost-effectiveness is associated with the cost of the drug, care costs, the loss of productivity due to disability following recurrent disease, individual patient risk for thromboembolism and bleeding, and the quality of anticoagulation control (i.e., TTR) which in turn is related to compliance, warfarin pharmacogenomics, and accessibility for regular INR tests.

We suggest that NOACs may be particularly cost-effective in Asian stroke patients for the following reasons. First, the risk of both recurrent thromboembolism and bleeding is higher in stroke patients than in patients without stroke. Moreover, as discussed above, Asians are at higher risk of warfarin-related $\mathrm{ICH}$, a devastating condition, than Caucasians. Second, patients with AF-related stroke have a poorer control of INR than those without stroke, probably because of more severe neurological disability and a lack of access to frequent INR monitoring. It has been shown that most (>70\%) AF-related stroke patients have lobar or territorial infarcts, ${ }^{42}$ and poor anticoagulation control is associated with the size of brain infarcts (Figure 1). ${ }^{43}$

Thus, Asian stroke patients more often face problems in using warfarin: difficulty in maintaining INR and frequent bleeding complications. In this regard, NOACs appear to be particularly cost-effective for Asian stroke patients. However, NOACs are expensive drugs and studies focusing on the cost-effectiveness of NOACs in Asian stroke patients are unavailable. Nevertheless, given the considerations so far discussed, we propose that the reimbursement policy for the use of NOACs should be more generous for Asian stroke patients.

\section{Viewing reimbursement guidelines for NOACs from strokologists' perspective}

The guidelines for the reimbursement of NOACs are summarized in Table 2. In Japan, Taiwan, Norway, Switzerland, Iceland, and the United Arab Emirates, there is no restriction as long as NOACs are prescribed on-label. The reimbursement
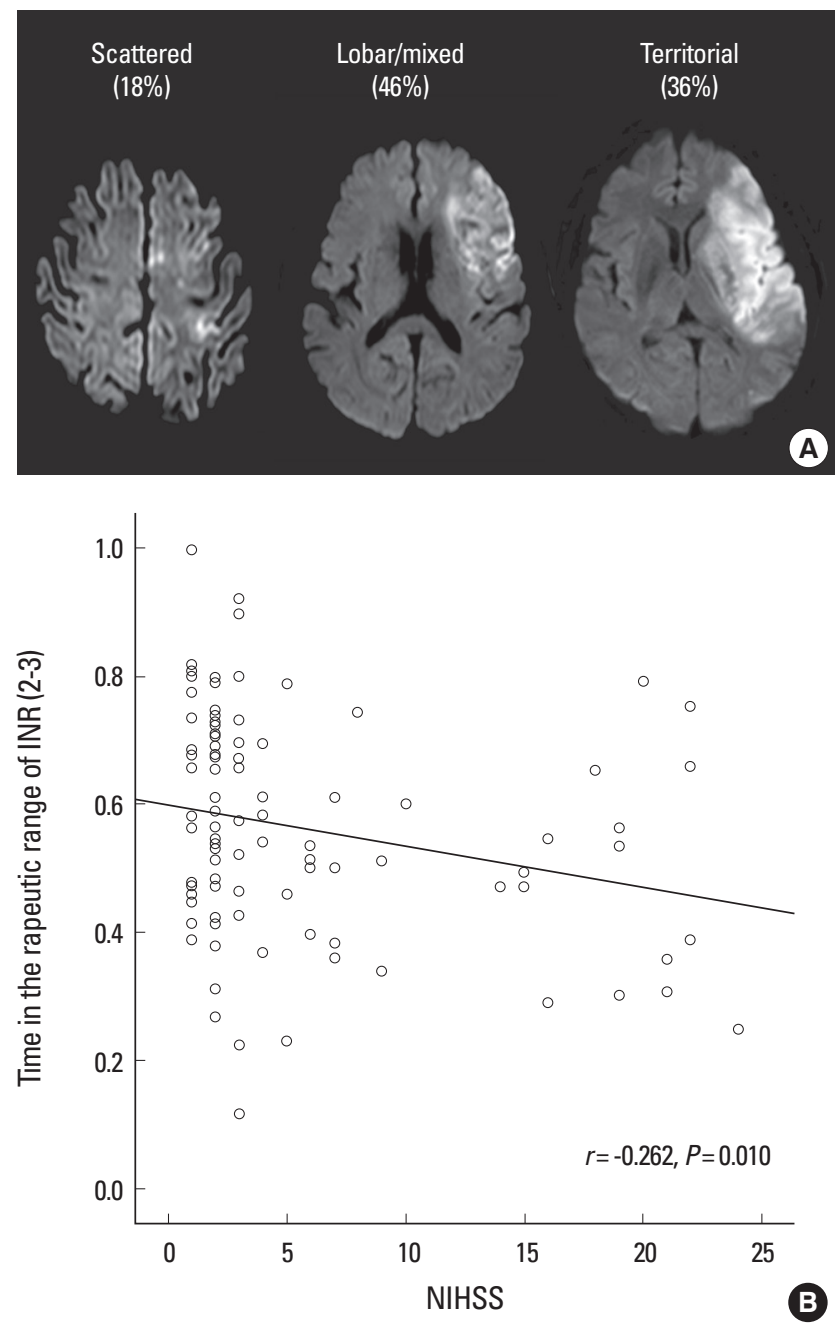

Figure 1. The relationship between stroke severity and the quality of anticoagulation control. (A) Most strokes related to atrial fibrillation are large cortical infarcts, especially among patients who were inadequately anticoagulated. (B) Patients with more severe neurological deficits had worse quality of anticoagulation. The time in therapeutic range of the international normalized ratio (INR) was negatively correlated with the baseline neurological deficits $(r=-0.262$, $P=0.010)$. Figure modified from Oh et al. ${ }^{42} \mathrm{NIHSS}=$ National Institutes of Health Stroke Scale.

guidelines for NOACs in some European countries, including the UK, France, and Germany, are based only on the $\mathrm{CHADS}_{2}$ score $(\geq 1)$. Other European countries and Canada include both $\mathrm{CHADS}_{2}$ score and the quality of anticoagulation control. For example, the provincial reimbursement guideline for NOACs in Canada includes (a) unable to tolerate warfarin, (b) INRs not well controlled on warfarin, or (c) unable to have INRs tested regularly, in patients with a $\mathrm{CHADS}_{2}$ score of $\geq 2$.

The guidelines for the reimbursement of NOACs in Korea are similar to those of Canada, but the accessibility (ability to have INR tested regularly) is not considered. The criteria for 'inadequate anticoagulation' appear to be too strict, especially during the maintenance period (Table 3 ). As a result, it is diffi- 
Table 2. Reimbursement of new oral anticoagulants

\begin{tabular}{|c|c|c|}
\hline Category & Country & No. of countries \\
\hline Full reimbursement & Japan, Norway, Switzerland, Taiwan, Iceland, United Arab Emirates & 6 \\
\hline $\mathrm{CHADS}_{2}$ score $\geq 1$ & United Kingdom, Bulgaria, France, Germany, Ireland, Luxembourg, Netherlands, Belgium & 8 \\
\hline $\mathrm{CHADS}_{2}$ score $\geq 1$ and poor control with warfarin & Scotland, Finland, Slovenia, Czech republic, Slovakia, Austria, Denmark, Sweden, Spain, Australia & 11 \\
\hline $\mathrm{CHADS}_{2}$ score $\geq 2$ and poor control with warfarin & Canada, Korea, Israel & 3 \\
\hline $\mathrm{CHADS}_{2}$ score $>3$ and HAS-BLED $>3$ & Italy & 1 \\
\hline Non-reimbursement & $\begin{array}{c}\text { U.S., Albania, Bosnia and Herzegovina, Croatia, Cyprus, Estonia, Greece, Hungary, Latvia, Lithuania, } \\
\text { Macedonia, Malaysia, Malta, New Zealand, Poland, Portugal, Singapore, Turkey }\end{array}$ & 18 \\
\hline
\end{tabular}

Table 3. The reimbursement guideline for new oral anticoagulants in Korea

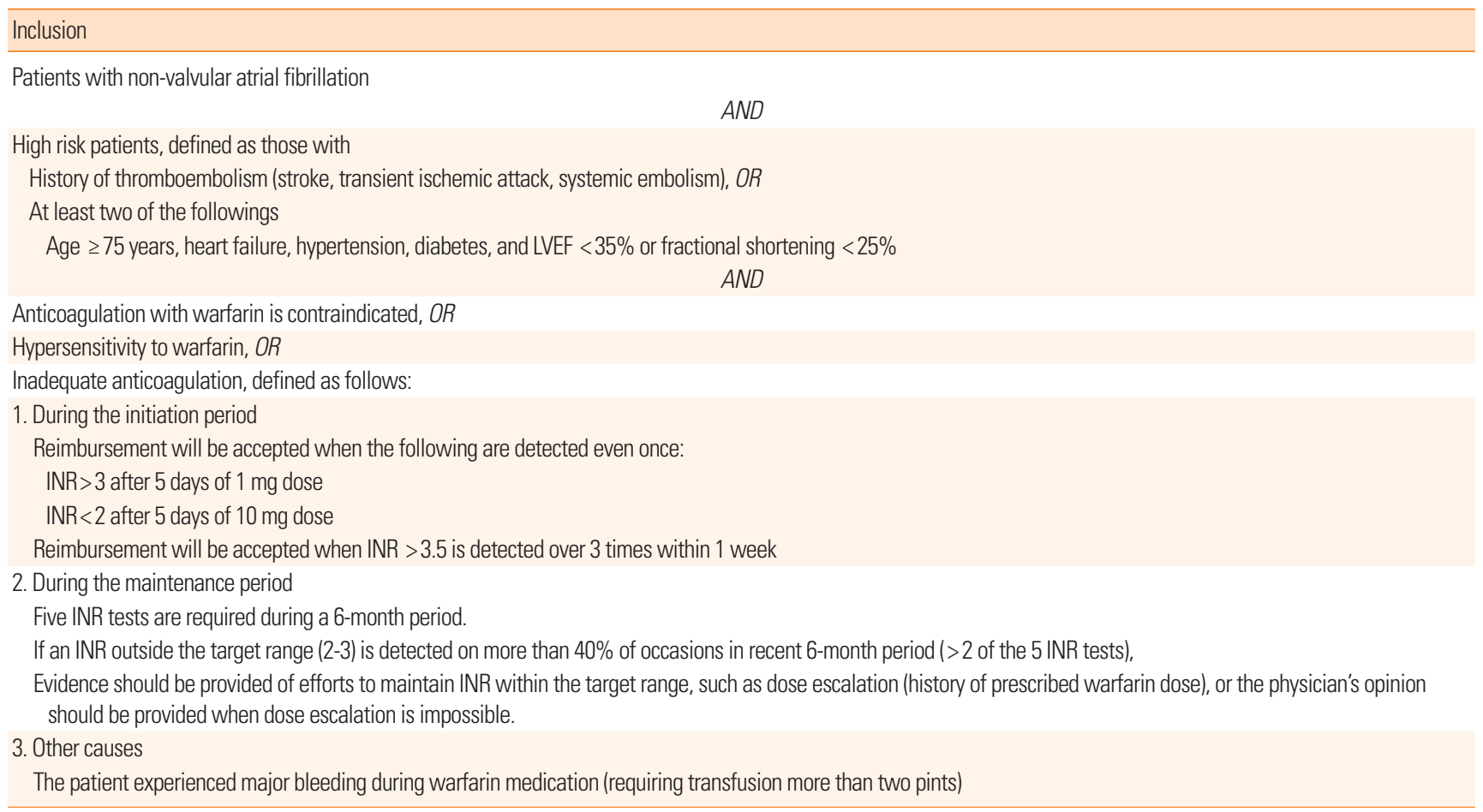

cult to prescribe NOACs to stroke patients with severe disability, or those who live in remote areas (e.g., on an island) and are thus unable to test INR regularly. The guideline also recommends a frequent change of warfarin dose (at least 5 times during 6 months) to monitor INR. This is in conflict with a randomized study comparing TTR between warfarin dose assessment every 4 weeks vs. every 12 weeks, which showed that frequent dose changes to monitor INR are unnecessary and result in temporary fluctuation of the INR..$^{44}$ Moreover, the guidelines state that reimbursement can be allowed if patients have a major bleeding complication during warfarin treatment. From the strokologist's point of view this does not make sense, because warfarin-associated $\mathrm{ICH}$ is frequently fatal.

We understand that the strict guidelines can be attributed to the high cost of NOACs, which may adversely affects the health budget, but we would suggest that the guidelines be more generous to Asian stroke patients, who are particularly vulnerable to the adverse effects of warfarin. We suggest that this approach may be more cost-effective than not using NOACs, because recurrent ischemic stroke or ICH will be very costly in this rapidly aging society. As discussed above, cost-effectiveness studies on Asian stroke patients are unavailable and should be performed in the future to answer this question.

\section{Conclusions}

AF is an emerging global epidemic in both high-income and low-income countries. Recently, the use of NOACs in AF patients has been rapidly increasing, but the cost of NOACs is unaffordable in low-income to middle-income countries. Consequently, the reimbursement guidelines for NOACs tend to be over-restrictive. However, the cost-effectiveness of NOACs will depend on the characteristics of patients as well as therapy pricing. Asian countries are facing population aging at a pace that is 

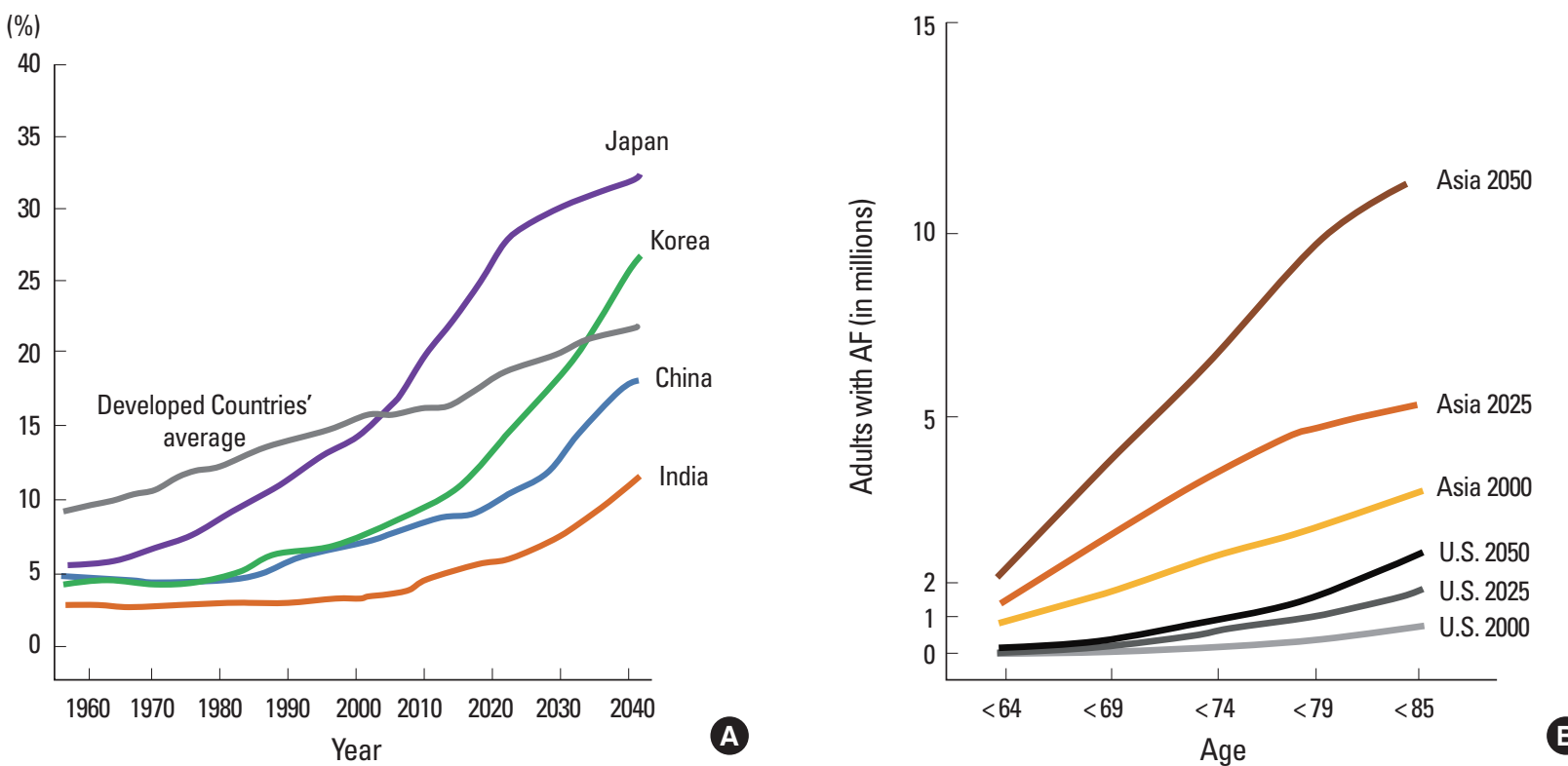

Figure 2. (A) Proportion of elderly population by country (age 65 years and over), (B) Number of cases of atrial fibrillation (AF) predicted by 2050. Source: Statistics Bureau, MIC; Ministry of Health, Labor and Welfare, United Nations; and Population Division, Department of Economic and Social Affairs, United Nations.

unprecedented and an increasing burden of stroke, particularly AF-related stroke. AF-related stroke is more disabling and more fatal than other stroke subtypes, and is expected to increase substantially in the decades to come (Figure 2). Compared to Caucasians, Asians more often develop hemorrhagic stroke and warfarin-related $\mathrm{ICH}$, as well as any stroke in the case of patients with $\mathrm{AF}$, and the benefit with NOACs vs. warfarin for preventing stroke and reducing anticoagulation-related $\mathrm{ICH}$ would be particularly high in Asians. Nevertheless, the current reimbursement guidelines are in general suboptimal. We suggest that guidelines for using NOACs should be more generous for Asian stroke patients.

In addition, as NOACs are expensive, continuous efforts should be made by healthcare providers and governors to find the ideal candidate for NOACs (most cost-effective group); this includes research to find genetic or clinical factors that predict the quality of anticoagulation control. ${ }^{45,46}$ Close communication is needed to arrive at a consensus decision regarding the coverage guideline for those patients who need NOACs, and to reduce the ever-increasing burden of AF-related stroke.

\section{References}

1. Gomes T, Mamdani MM, Holbrook AM, Paterson JM, Juurlink DN. Persistence with therapy among patients treated with warfarin for atrial fibrillation. Arch Intern Med 2012;172:16871689.

2. Gallagher AM, Setakis E, Plumb JM, Clemens A, van Staa TP.
Risks of stroke and mortality associated with suboptimal anticoagulation in atrial fibrillation patients. Thromb Haemost 2011; 106:968-977.

3. Connolly SJ, Pogue J, Eikelboom J, Flaker G, Commerford P, Franzosi MG, et al. Benefit of oral anticoagulant over antiplatelet therapy in atrial fibrillation depends on the quality of international normalized ratio control achieved by centers and countries as measured by time in therapeutic range. Circulation 2008; 118:2029-2037.

4. Connolly SJ, Ezekowitz MD, Yusuf S, Eikelboom J, Oldgren J, Parekh A, et al. Dabigatran versus warfarin in patients with atrial fibrillation. N Engl J Med 2009;361:1139-1151.

5. Patel MR, Mahaffey KW, Garg J, Pan G, Singer DE, Hacke W, et al. Rivaroxaban versus warfarin in nonvalvular atrial fibrillation. N Engl J Med 2011;365:883-891.

6. Granger CB, Alexander JH, McMurray JJ, Lopes RD, Hylek EM, Hanna M, et al. Apixaban versus warfarin in patients with atrial fibrillation. N Engl J Med 2011;365:981-992.

7. Giugliano RP, Ruff CT, Braunwald E, Murphy SA, Wiviott SD, Halperin JL, et al. Edoxaban versus warfarin in patients with atrial fibrillation. N Engl J Med 2013;369:2093-2104.

8. Palareti G, Leali N, Coccheri S, Poggi M, Manotti C, D’Angelo A, et al. Bleeding complications of oral anticoagulant treatment: an inception-cohort, prospective collaborative study (ISCOAT). Italian Study on Complications of Oral Anticoagulant Therapy. Lancet 1996;348:423-428.

9. Phillips KW, Ansell J. The clinical implications of new oral anticoagulants: will the potential advantages be achieved? Thromb 
Haemost 2010;103:34-39.

10. Amadeus Investigators, Bousser MG, Bouthier J, Buller HR, Cohen AT, Crijns H, et al. Comparison of idraparinux with vitamin $\mathrm{K}$ antagonists for prevention of thromboembolism in patients with atrial fibrillation: a randomised, open-label, noninferiority trial. Lancet 2008;371:315-321.

11. Albers GW, Diener HC, Frison L, Grind M, Nevinson M, Partridge $S$, et al. Ximelagatran vs warfarin for stroke prevention in patients with nonvalvular atrial fibrillation: a randomized trial. JAMA 2005;293:690-698.

12. Gomez-Outes A, Terleira-Fernandez AI, Suarez-Gea ML, Vargas-Castrillon E. Dabigatran, rivaroxaban, or apixaban versus enoxaparin for thromboprophylaxis after total hip or knee replacement: systematic review, meta-analysis, and indirect treatment comparisons. BMJ 2012;344:e3675.

13. Ntaios G, Papavasileiou V, Diener HC, Makaritsis K, Michel P. Nonvitamin-K-antagonist oral anticoagulants in patients with atrial fibrillation and previous stroke or transient ischemic attack: a systematic review and meta-analysis of randomized controlled trials. Stroke 2012;43:3298-3304.

14. Eckman MH, Singer DE, Rosand J, Greenberg SM. Moving the tipping point: the decision to anticoagulate patients with atrial fibrillation. Circ Cardiovasc Qual Outcomes 2011;4:14-21.

15. Furie KL, Goldstein LB, Albers GW, Khatri P, Neyens R, Turakhia MP, et al. Oral antithrombotic agents for the prevention of stroke in nonvalvular atrial fibrillation: a science advisory for healthcare professionals from the American Heart Association/ American Stroke Association. Stroke 2012;43:3442-3453.

16. Ruff CT, Giugliano RP, Braunwald E, Hoffman EB, Deenadayalu N, Ezekowitz MD, et al. Comparison of the efficacy and safety of new oral anticoagulants with warfarin in patients with atrial fibrillation: a meta-analysis of randomised trials. Lancet 2014;383:955-962.

17. Thrift AG, Dewey HM, Macdonell RA, McNeil JJ, Donnan GA. Incidence of the major stroke subtypes: initial findings from the North East Melbourne Stroke Incidence Study (NEMESIS). Stroke 2001;32:1732-1738.

18. Klatsky AL, Friedman GD, Sidney S, Kipp H, Kubo A, Armstrong MA. Risk of hemorrhagic stroke in Asian American ethnic groups. Neuroepidemiology 2005;25:26-31.

19. Ayala C, Croft JB, Greenlund KJ, Keenan NL, Donehoo RS, Malarcher AM, et al. Sex differences in US mortality rates for stroke and stroke subtypes by race/ethnicity and age, 19951998. Stroke 2002;33:1197-1201.

20. Koennecke HC. Cerebral microbleeds on MRI: prevalence, associations, and potential clinical implications. Neurology 2006; 66:165-171.

21. Lee SH, Bae HJ, Yoon BW, Kim H, Kim DE, Roh JK. Low con- centration of serum total cholesterol is associated with multifocal signal loss lesions on gradient-echo magnetic resonance imaging: analysis of risk factors for multifocal signal loss lesions. Stroke 2002;33:2845-2849.

22. Strazzullo P, D’Elia L, Kandala NB, Cappuccio FP. Salt intake, stroke, and cardiovascular disease: meta-analysis of prospective studies. BMJ 2009;339:b4567.

23. Wong KS, Chan YL, Liu JY, Gao S, Lam WW. Asymptomatic microbleeds as a risk factor for aspirin-associated intracerebral hemorrhages. Neurology 2003;60:511-513.

24. Charidimou A, Shakeshaft C, Werring DJ. Cerebral microbleeds on magnetic resonance imaging and anticoagulant-associated intracerebral hemorrhage risk. Front Neurol 2012;3:133.

25. Smith EE, Rosand J, Knudsen KA, Hylek EM, Greenberg SM. Leukoaraiosis is associated with warfarin-related hemorrhage following ischemic stroke. Neurology 2002;59:193-197.

26. Shen AY, Yao JF, Brar SS, Jorgensen MB, Chen W. Racial/ethnic differences in the risk of intracranial hemorrhage among patients with atrial fibrillation. J Am Coll Cardiol 2007;50:309315.

27. Choi-Kwon S LH, Kwon SU, Kim JS. Use of post-stroke herbal treatment in stroke patients. Kor J Stroke 2003;5:64-69.

28. Kelner M, Wellman B. Health care and consumer choice: medical and alternative therapies. Soc Sci Med 1997;45:203-212.

29. Wong RS, Cheng G, Chan TY. Use of herbal medicines by patients receiving warfarin. Drug Saf2003;26:585-588.

30. Wallentin L, Yusuf S, Ezekowitz MD, Alings M, Flather M, Franzosi MG, et al. Efficacy and safety of dabigatran compared with warfarin at different levels of international normalised ratio control for stroke prevention in atrial fibrillation: an analysis of the RE-LY trial. Lancet 2010;376:975-983.

31. Hori M, Connolly SJ, Zhu J, Liu LS, Lau CP, Pais P, et al. Dabigatran versus warfarin: effects on ischemic and hemorrhagic strokes and bleeding in Asians and non-Asians with atrial fibrillation. Stroke 2013;44:1891-1896.

32. JCS Joint Working Group. Guidelines for pharmacotherapy of atrial fibrillation (JCS 2008): digest version. Circ J 2010;74: 2479-2500.

33. Takahashi H, Wilkinson GR, Caraco Y, Muszkat M, Kim RB, Kashima T, et al. Population differences in S-warfarin metabolism between CYP2C9 genotype-matched Caucasian and Japanese patients. Clin Pharmacol Ther 2003;73:253-263.

34. Rieder MJ, Reiner AP, Gage BF, Nickerson DA, Eby CS, McLeod $\mathrm{HL}$, et al. Effect of VKORC1 haplotypes on transcriptional regulation and warfarin dose. NEngl J Med 2005;352:2285-2293.

35. Takahashi H, Wilkinson GR, Nutescu EA, Morita T, Ritchie $\mathrm{MD}$, Scordo MG, et al. Different contributions of polymorphisms in VKORC1 and CYP2C9 to intra- and inter-population dif- 
ferences in maintenance dose of warfarin in Japanese, Caucasians and African-Americans. Pharmacogenet Genomics 2006;16:101110.

36. Hori M, Matsumoto M, Tanahashi N, Momomura S, Uchiyama S, Goto S, et al. Rivaroxaban vs. warfarin in Japanese patients with atrial fibrillation - the J-ROCKET AF study. Cir J2012;76: 2104-2111.

37. Ogawa S, Shinohara Y, Kanmuri K. Safety and efficacy of the oral direct factor xa inhibitor apixaban in Japanese patients with non-valvular atrial fibrillation. - the ARISTOTLE-J study. Circ J2011;75:1852-1859.

38. Chiang CE, Wang KL, Lip GY. Stroke prevention in atrial fibrillation: an Asian perspective. Thromb Haemost 2014;111:789797.

39. Kamel H, Johnston SC, Easton JD, Kim AS. Cost-effectiveness of dabigatran compared with warfarin for stroke prevention in patients with atrial fibrillation and prior stroke or transient ischemic attack. Stroke 2012;43:881-883.

40. Kamel H, Easton JD, Johnston SC, Kim AS. Cost-effectiveness of apixaban vs warfarin for secondary stroke prevention in atrial fibrillation. Neurology 2012;79:1428-1434.

41. Harrington AR, Armstrong EP, Nolan PE Jr, Malone DC. Costeffectiveness of apixaban, dabigatran, rivaroxaban, and warfarin for stroke prevention in atrial fibrillation. Stroke 2013;44:16761681.

42. Oh S, Kim SJ, Ryu SK, Kim GM, Chung CS, Lee KH, et al. The determinants of stroke phenotypes were different from the predictors (CHADS2 and CHA2DS2-VASc) of stroke in patients with atrial fibrillation: a comprehensive approach. BMC Neurol 2011;11:107.

43. Ay H, Arsava EM, Gungor L, Greer D, Singhal AB, Furie KL, et al. Admission international normalized ratio and acute infarct volume in ischemic stroke. Ann Neurol 2008;64:499-506.

44. Schulman S, Parpia S, Stewart C, Rudd-Scott L, Julian JA, Levine M. Warfarin dose assessment every 4 weeks versus every 12 weeks in patients with stable international normalized ratios: a randomized trial. Ann Intern Med 2011;155:653-659, W201W203.

45. Apostolakis S, Sullivan RM, Olshansky B, Lip GY. Factors affecting quality of anticoagulation control among patients with atrial fibrillation on warfarin: the SAMe-TT2R2 score. Chest 2013;144:1555-1563.

46. Boriani G. Predicting the quality of anticoagulation during warfarin therapy: the basis for an individualized approach. Chest 2013;144:1437-1438. 